STUDI

FRANCESI

\section{Studi Francesi}

Rivista quadrimestrale fondata da Franco Simone

194 (LXV | II) | 2021

Baudelaire et son cénacle

\title{
AGRIPPA D’AUBIGNÉ, Les Avantures du baron de Foneste
}

\section{Laura Rescia}

\section{(2) OpenEdition \\ Journals}

\section{Edizione digitale}

URL: https://journals.openedition.org/studifrancesi/44958

DOI: $10.4000 /$ studifrancesi.44958

ISSN: 2421-5856

\section{Editore}

Rosenberg \& Sellier

\section{Edizione cartacea}

Data di pubblicazione: 1 août 2021

Paginazione: 365

ISSN: 0039-2944

Notizia bibliografica digitale

Laura Rescia, «AgripPa d'Aubigné, Les Avantures du baron de Fæneste», Studi Francesi [Online], 194 (LXV I

II) | 2021, online dal 01 septembre 2021, consultato il 15 octobre 2022. URL: http://

journals.openedition.org/studifrancesi/44958 ; DOI: https://doi.org/10.4000/studifrancesi.44958

Questo documento è stato generato automaticamente il 15 octobre 2022.

\section{(c) (i) ()}

Creative Commons - Attribuzione - Non commerciale - Non opere derivate 4.0 Internazionale - CC BYNC-ND 4.0

https://creativecommons.org/licenses/by-nc-nd/4.0/ 


\title{
AGRIPPA D'AUBIGNÉ, Les Avantures du baron de Foneste
}

\author{
Laura Rescia
}

\section{NOTIZIA}

AGRIPPA D’AUBIGNÉ, Les Avantures du baron de Fœneste, éd. J-R. Fanlo, M-M. Fragonard et G.

Schrenck, in Euvres, t. VII, dir. J.R. Fanlo, M.M. Fragonard et G. Schrenck, Paris,

Classiques Garnier, 2020, 477 pp.

1 Questa nuova edizione critica, corredata da un saggio introduttivo di un centinaio di pagine, si colloca a molti anni dall'ultima edizione moderna (La Pléiade, 1969): un cinquantennio in cui la critica si è adoperata per illuminare la molteplicità degli aspetti di un testo ricco e complesso, qui presentato - in lodevole controtendenza - in versione non modernizzata. Gli editori, quattro tra i maggiori specialisti di d'Aubigné, hanno realizzato un lavoro dettagliato e di grande utilità. L'introduzione permette un approccio all'opera che felicemente e sapientemente coniuga metodologie complementari: l'approccio storico-biografico, necessario per dipanare la vicenda editoriale in relazione agli avvenimenti coevi della storia di Francia e della vita dell'autore; quello squisitamente letterario, che rintraccia in un testo composito la compresenza di generi (modello picaresco, dialogo filosofico, narrazione intersecata tra facezia e histoire comique), l'emergere dell'eroe guascone, all'incrocio tra l'evoluzione del miles gloriosius e riflesso di quella letteratura dei vagabondi che tanto successo riscuote tra Cinque e Seicento; per poi analizzarne la funzione dialogica, alla luce delle diverse edizioni, sfruttando in tal modo la lezione della critica variantistica. Successivamente ci si focalizza sulla funzione satirica, in evidente connessione all'attualità politica, militare, letteraria e sociale, in cui personaggi, spazi e tempi trovano una loro configurazione "realista", seppur non priva di distorsioni. La questione del plurilinguismo testuale viene affrontata nell'ottica della linguistica storica ed ancora in relazione alle varianti testuali. Per ultimo, si dà conto del "labirinto 
editoriale", con un'ottica filologica arricchita da considerazioni di bibliografia materiale.

2 Il testo, annotato con grande ricchezza per chiarirne ogni dimensione, è seguito dall'apparato variantistico, da un'ottima bibliografia e da numerosi indici. 